in vivo $34: 3291-3299(2020)$

doi:10.21873/invivo.12167

\title{
Does the Addition of Abiraterone to Castration Affect the Reduction in Bone Mineral Density?
}

\author{
SHIORI NAKAJIMA ${ }^{1}$, TAKAMITSU INOUE ${ }^{1}$, MINGGUO HUANG $^{1}$, KOICHIRO TAKAYAMA $^{2}$, \\ SOKI KASHIMA $^{1}$, RYOHEI YAMAMOTO ${ }^{1}$, ATSUSHI KOIZUMI ${ }^{1}$, TAKETOSHI NARA ${ }^{1}$, \\ KAZUYUKI NUMAKURA ${ }^{1}$, MITSURU SAITO ${ }^{1}$, SHINTARO NARITA $^{1}$, \\ MASATOMO MIURA ${ }^{3}$, SHIGERU SATOH ${ }^{4}$ and TOMONORI HABUCHI ${ }^{1}$ \\ ${ }^{1}$ Department of Urology, Akita University Graduate School of Medicine, Akita, Japan; \\ ${ }^{2}$ Department of Urology, Municipal Yokote Hospital, Akita, Japan; \\ ${ }^{3}$ Department of Pharmacy, Akita University Hospital, Akita, Japan; \\ ${ }^{4}$ Center for Kidney Disease and Transplantation, Akita University Hospital, Akita, Japan
}

\begin{abstract}
Background/Aim: The in vivo effect of abiraterone on bone mineral density (BMD) in addition to androgen deprivation therapy was examined using a murine model. Materials and Methods: The mice were separated into the following groups: control, abiraterone, castration, and castration+abiraterone. The percentage change in the ratio of bone to tissue volume $(B V / T V)$, number of osteoblasts and osteoclasts, and the serum level of bone markers were compared on day 21. Results: The BV/TV ratio of the abiraterone, castration, and castration+abiraterone groups was lower than that of the control group. However, the change in the BV/TV ratio in the castration+abiraterone group was not significantly different from that in the castration group. There was no significant difference in the serum TRAP5b level and the number of osteoclasts and osteoblasts between the castration+abiraterone and the castration groups. Conclusion: The addition of abiraterone to castration did not affect BMD in the murine model.
\end{abstract}

The recent development of antitumor drugs has been contributing to the improvement of survival in prostate cancer patients. The management of skeletal-related events (SREs) is crucial in patients with prostate cancer due to the

This article is freely accessible online.

Correspondence to: Takamitsu Inoue, MD, Department of Renal and Urological Surgery, International University of Health and Welfare School of Medicine, 852 Hatakeda, Narita, Chiba, 2860124, Japan. Tel: +81 476355600, Fax: +81 476355586, e-mail: takmitz@gmail.com; takmitz@iuhw.ac.jp

Key Words: Androgen deprivation therapy, bone mineral density, osteoblasts, micro-computed tomography, bone microenvironment. high frequency of bone metastasis and the effect of androgen deprivation therapy (ADT) in reducing bone mineral density (BMD). Bone metastasis appears frequently in prostate cancer patients, and the occurrence of SREs can greatly affect both their quality of life and prognosis. ADT is effective in about $80 \%$ of patients with hormone naïve prostate cancer (1). However, the treatment causes a variety of adverse events, including BMD reduction (2). Approximately $45 \%$ of prostate cancer patients who receive ADT are reported to have osteoporosis (3).

ADT increases RANK/RANKL signaling, leading to stimulated osteoblasts (4). Increased RANKL signaling activates osteoclasts, which promote bone resorption and reduce BMD (5). In a murine castration model, the use of osteoprotegerin (OPG) has been shown to prevent the RANKL-enhanced activation of osteoclasts and the ADTinduced acceleration of bone metastasis (6). A similar effect has been reported using zoledronic acid (7). Although ADT suppresses the growth of cancer cells, it may potentially promote bone metastasis in castration-resistant prostate cancer (CRPC) by reducing BMD.

There are currently several options available for the initial treatment of metastatic hormone-sensitive prostate cancer (HNPC), including luteinizing hormone-releasing hormone (LH-RH) or castration monotherapy (8), LHRH+docetaxel (9), and LH-RH+abiraterone+PSL (10). The LATITUDE study recently showed that administering abiraterone to HNPC patients significantly increased the time to symptomatic skeletal events (10). On the other hand, the STAMPEDE study showed that the time to SRE in the abiraterone and docetaxel groups was almost similar to that in the LATITUDE study (11). In the COU-AA-301 and 302 studies of patients with mCRPC before and after docetaxel, the time to SRE was significantly prolonged in the abiraterone-treated group, compared with the placebo 

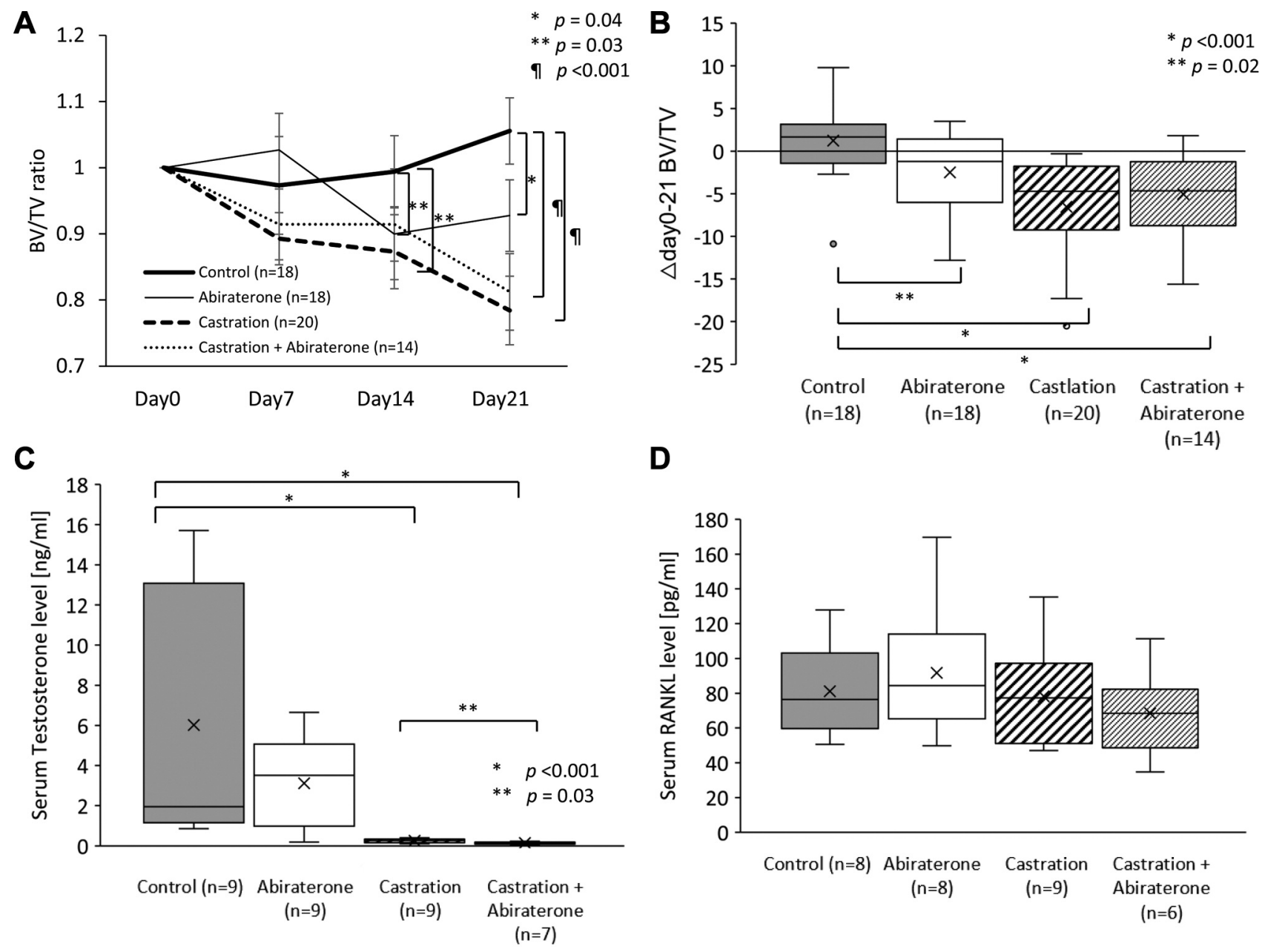

D

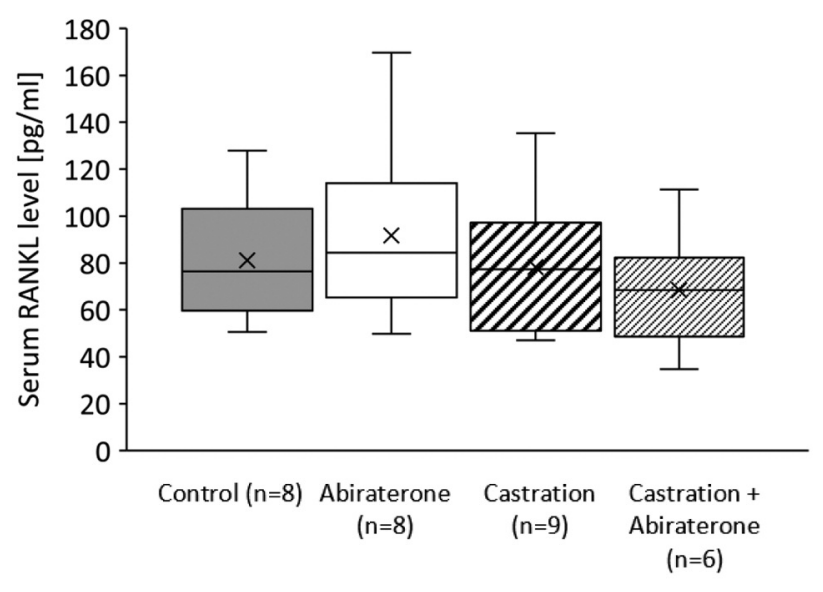

Figure 1. Continued

group. Moreover, the addition of bone modifying agents (BMA) further extended the time to SRE and overall survival (12).

A previous in vitro study that observed the direct effect of abiraterone on osteoclasts and osteoblasts indicated that hormone therapy inhibits osteoclasts and promotes osteoblast differentiation and bone matrix deposition (13). This in vitro study may support the superiority of abiraterone therapy for bone metastasis. However, ADT activates osteoclasts and promotes bone resorption (6) and abiraterone may reduce adrenal androgens and further activate osteoclasts by lowering androgen levels. It has not yet been elucidated in clinical studies whether the effect of abiraterone on improving the time to SREs is due only to its inhibitory effect on the cancer cells, or if this also comprises a direct effect on osteoblasts and osteoclasts. In this study, we investigated the additional in vivo effect of abiraterone to ADT in the bone microenvironment using both non-tumorbearing castrated and non-castrated mice.

\section{Materials and Methods}

Animal. This animal research was performed with the approval of the institutional review board and animal research ethics committee, based on the Akita University Animal Research Ethics Guidelines (Approval number: a-1-3022). Male retired breeder (24 weeks or older) Balb/c nu/nu mice were purchased from Japan SLC, Inc. (Shizuoka, Japan). These were kept in individual cages with food available ad libitum. The mice were divided into a control group, an abiraterone group, a castration group, and a castration+abiraterone group. Abiraterone was administered to each mouse five times a week before being suspended for two days. Micro-computed tomography imaging was performed once weekly (days $0,7,14$, and 21). All mice were euthanized on day 21 by cervical dislocation, after blood had been collected from the ventricle under anesthesia using isoflurane. After euthanasia, the lower limbs of the mice were frozen in liquid nitrogen and stored at $-80^{\circ} \mathrm{C}$.

Abiraterone. In oral gavage administration, abiraterone acetate 400 $\mathrm{mg} / \mathrm{kg}$ body weight/day was dissolved in a solvent of $13 \mathrm{ml} / \mathrm{kg}$ body weight of $95 \%$ peanut oil and $5 \%$ benzyl benzoate at $37^{\circ} \mathrm{C}$ for 24 $\mathrm{h}$. In this way, $30 \mathrm{mg} / \mathrm{ml}$ of abiraterone acetate solution was 


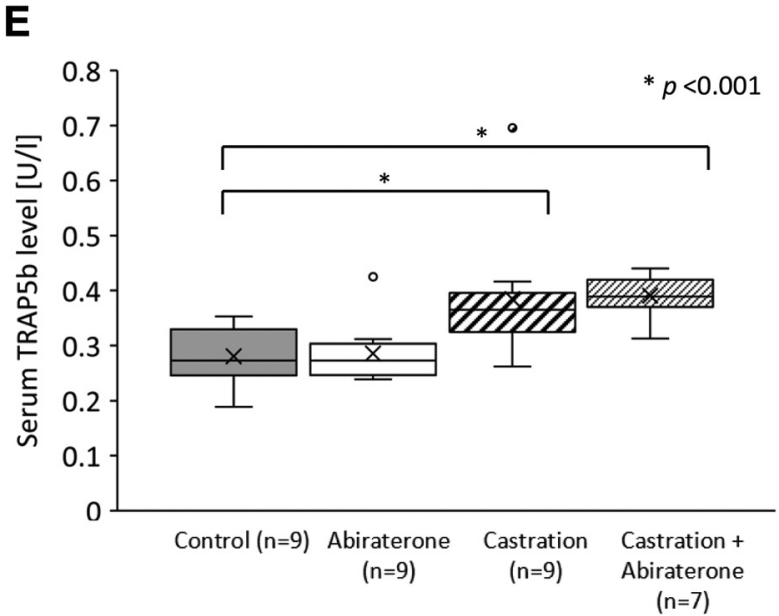

G
$\mathbf{F}$

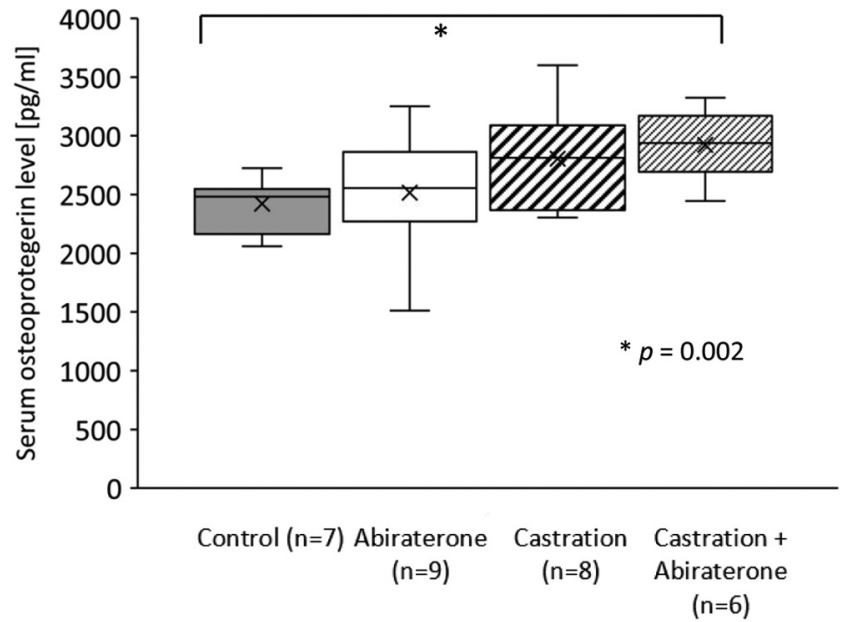

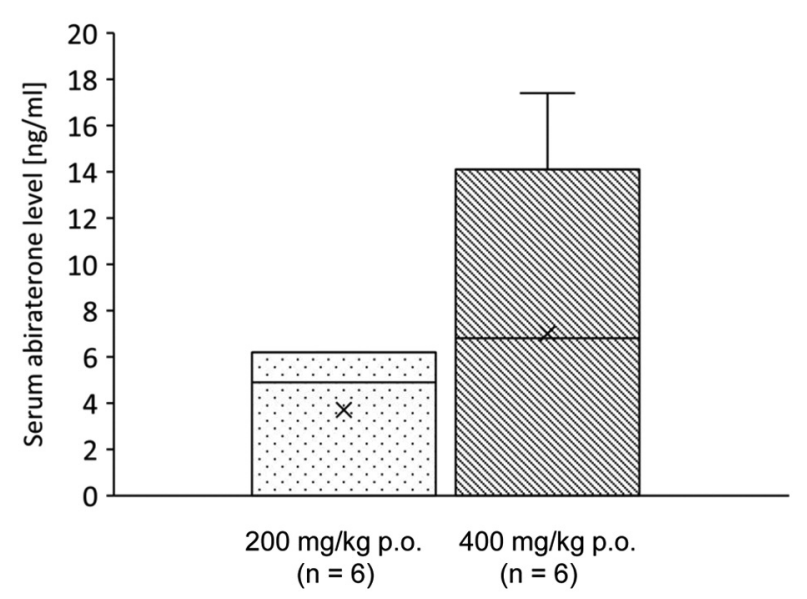

Figure 1. Effect of oral administration of abiraterone on cancellous bone in mice. A) Comparison of the ratio of bone to tissue volume (BV/TV) of cancellous bone over time relative to day 0 using bone density analysis by micro-CT. The BV/TV ratio of the abiraterone, castration, and castration+abiraterone groups decreased significantly, compared to the control group $(p=0.04, p=0.03, p<0.001)$. B) Comparison of the difference in cancellous bone BV/TV absolute value between days 0 and 21. Sday 0-21 BV/TV of the abiraterone, castration, and castration+abiraterone groups decreased significantly, compared to the control group $(p=0.02, p<0.001, p<0.001)$. C) Comparison of mouse testosterone blood levels. Testosterone levels in the castration and the castration+abiraterone groups were significantly lower than those in the control group ( $p<0.001$, $p<0.001)$. Testosterone levels in the castration and the castration+abiraterone groups were significantly lower than those in the abiraterone group $(p=0.001, p=0.03)$. D) Comparison of mouse RANKL blood levels. E) Comparison of mouse TRAP5b blood levels. The TRAP5b concentration was significantly higher in the castration and castration+abiraterone groups than in the control group $(p<0.001, p<0.001)$. F) Comparison of mouse $O P G$ blood levels. OPG concentration in the castration+abiraterone group was significantly higher than that in the control group ( $p=0.002)$. G) Comparison of mouse abiraterone trough blood levels.

administrated. In the group that did not receive abiraterone, only a solvent of $95 \%$ peanut oil and 5\% benzyl benzoate was administered (14).

Bone mineral density measurement. Both tibias in each mouse were scanned using a micro-CT (CT: CosmoScanGXII, Rigaku Co., Tokyo, Japan). The mean cancellous bone volume (BV) and tissue volume (TV) were measured, and the bone volume fraction (BV/TV) was calculated in a range of 100 slices $(9 \mu \mathrm{m} / \mathrm{slice})$ perpendicular to the long axis from the proximal edge of the tibia below the epiphyseal line (Figure 1). The bone analysis was performed using software (Bone Analysis software; Rigaku Co., Tokyo, Japan) attached to the micro-CT. The cancellous BV/TV was divided by each day 0 value to calculate a relative BV/TV change ratio. Moreover, the difference in cancellous bone $\mathrm{BV} / \mathrm{TV}$ between day 0 and day 21 ( $\Delta$ day $0-21 \mathrm{BV} / \mathrm{TV}$ ) was calculated.

Castration. The mice in the castrated group underwent bilateral orchiectomy one day before the initiation of abiraterone. For castration, the mice were anesthetized with isoflurane, and bilateral 

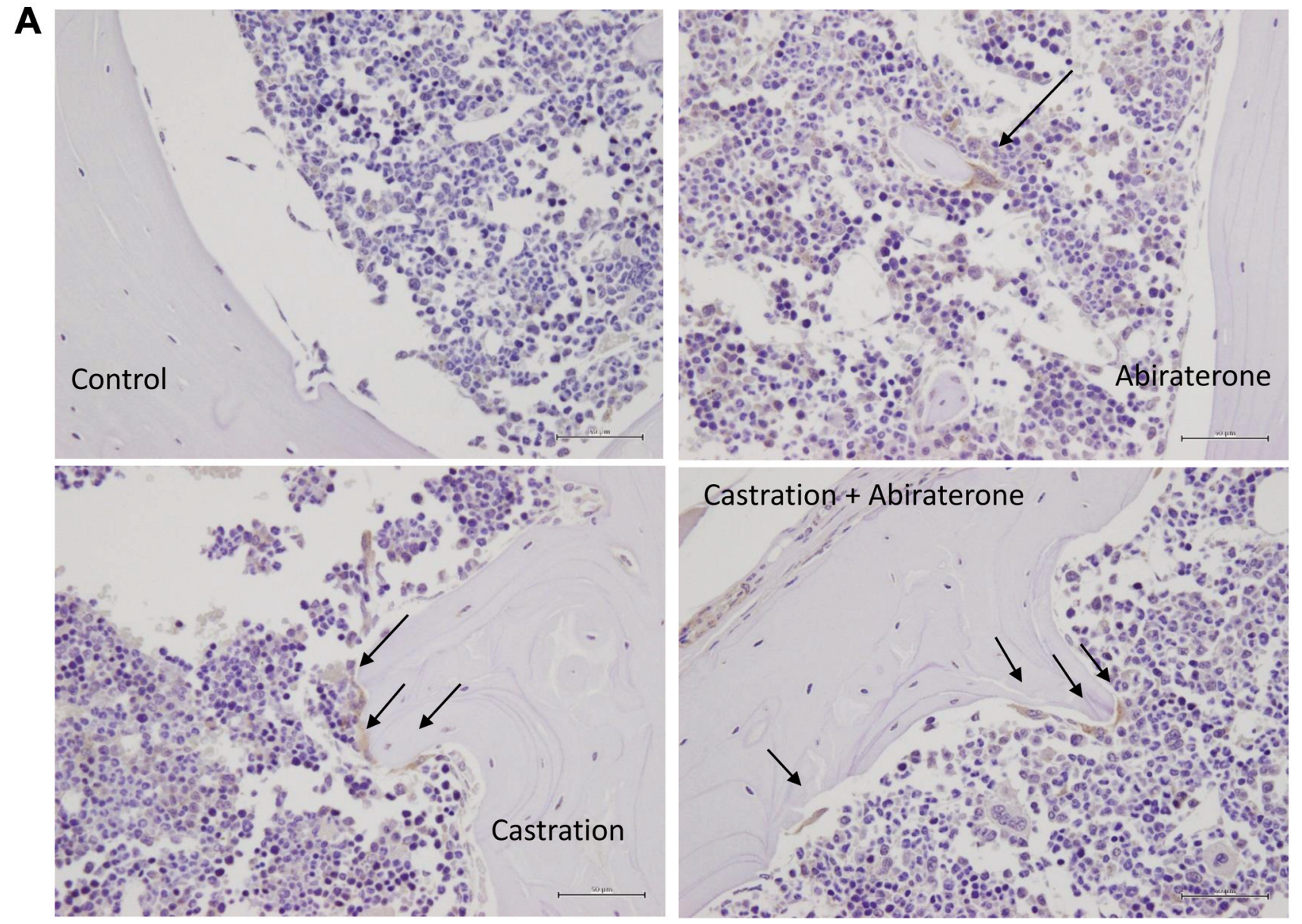

Figure 2. Continued

testes were removed through midline abdominal incision. The fascia and skin were continuously sutured with 5-0 vicryl ${ }^{\circledR}$.

Measurement of the serum levels. At euthanasia, a blood sample was collected from the left ventricle using a 26-gauge needle with a 1 $\mathrm{ml}$ syringe under general anesthesia. Blood samples were centrifuged at 3,000 revolutions per min for $10 \mathrm{~min}$, and serum was stored at $-80^{\circ} \mathrm{C}$ until analysis. Serum testosterone, receptor activator of nuclear factor kappa-B ligand (RANKL), TRAP5b, and OPG were measured using a testosterone (mouse/rat) enzyme-linked immunosorbent assay (ELISA) kit (\# K7418-100; Bio Vision Incorporated, Milpitas, CA, USA) mouse TRANCE/RANK L/TNFSF11 Quantikine ELISA Kit (\# MTR00; R \& D Systems, Inc., Minneapolis, MN, USA), mouseTRAP ${ }^{\mathrm{TM}}$ Assay (TRACP 5b ELISA) kit (\# DS-SBTR103; Immunodiagnostic Systems, Boldon, UK), and mouse Osteoprotegerin/TNFRSF11B Quantikine ELISA Kit (\# MOP00; R \& D Systems, Inc.).

The other group of mice was prepared for the measurement of plasma abiraterone level. The blood sample for the measurement of the plasma trough level of abiraterone was collected in the morning before the administration of abiraterone on the third day after the initiation of oral gavage. The plasma level of abiraterone was measured by high-performance liquid chromatography (HPLC).
Briefly, following the addition of sorafenib as an internal standard for a $400 \mu \mathrm{l}$ plasma sample $(10 \mathrm{ng} / 10 \mu \mathrm{l}$ methanol), the plasma sample was diluted with $600 \mu \mathrm{l}$ of water. The mixture was applied to an Oasis HLB extraction cartridge (Nihon Waters, Tokyo, Japan) that had been activated with methanol and water $(1.0 \mathrm{ml}$ each). The cartridge was washed with $1.0 \mathrm{ml}$ of water and $1.0 \mathrm{ml}$ of $20 \%$ aqueous methanol, and eluted with $1.0 \mathrm{ml}$ of $100 \%$ methanol. The eluate was evaporated to dryness in a vacuum at $40^{\circ} \mathrm{C}$ using a rotary evaporator (Iwaki, Tokyo, Japan). The residue was dissolved in 20 $\mu \mathrm{l}$ methanol, and $20 \mu \mathrm{l}$ of the mobile phase was added to the sample. A $20 \mu \mathrm{l}$ aliquot of the sample was processed by HPLC. The HPLC system comprised a PU-2080 plus chromatography pump (JASCO, Tokyo, Japan) equipped with a CAPCELL PAK C18 MG П HPLC column (250 mm×4.6 mm I.D.; Shiseido, Tokyo, Japan), a UV-2075 light source, and an ultraviolet detector (JASCO). The mobile phase was water-acetonitrile $(45: 55, \mathrm{v} / \mathrm{v})$, which was degassed in an ultrasonic bath before use. The flow rate was $0.8 \mathrm{ml} / \mathrm{min}$ at ambient temperature and sample detection was performed at $260 \mathrm{~nm}$.

Immunohistochemistry. The lower leg, including the femur, patella, and tibia, was obtained from the mice after euthanasia. Specimens were fixed with $4 \%$ paraformaldehyde and decalcified using $12 \%$ ethylenediaminetetraacetic acid for $72 \mathrm{~h}$. Thereafter, the specimen 

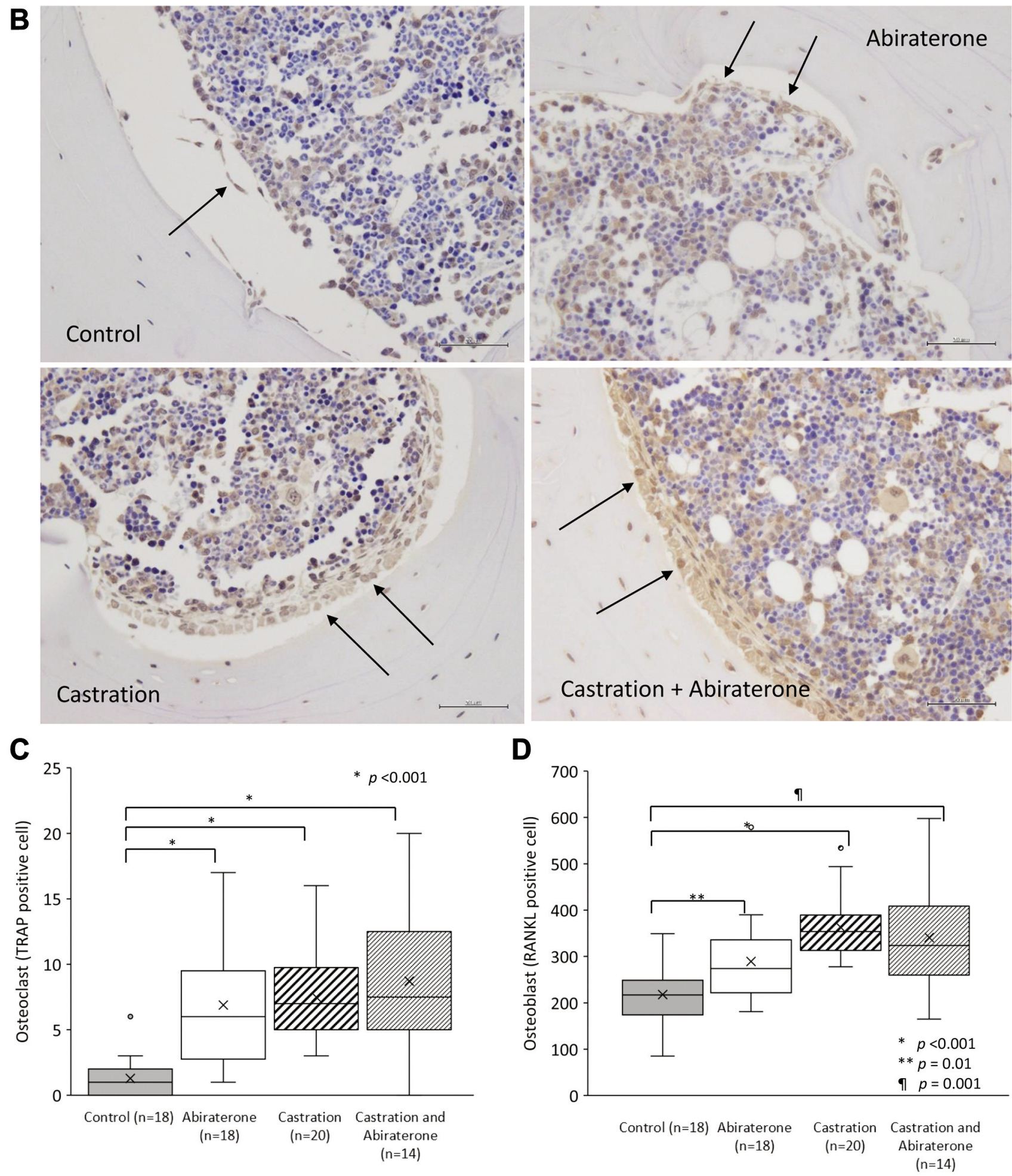

Figure 2. Effect of oral administration of abiraterone on the bone tissue of mice. A) Images of representative osteoclasts in a femur specimen of the control, abiraterone, castration, and castration+abiraterone groups. B) A photograph of a representative osteoblast in a femur specimen. C) Comparison of the number of TRAP-staining positive osteoclasts in the femoral cross section. This was significantly higher in the castration and castration+abiraterone groups than the control group $(p<0.001, p<0.001)$. D) Comparison of the number of RANKL-positive osteoblasts in femoral cross-sections. The abiraterone, castration and castration+abiraterone groups had significantly more than the control group ( $p=0.01, p<0.001$, $p=0.001)$. 
was paraffin-embedded and sliced into $5 \mu \mathrm{m}$ thick sections perpendicular to the long axis of the femur at the level of $2 \mathrm{~mm}$ proximal to the distal edge. The specimen was stained using a rabbit polyclonal primary antibody against TRAP at $100 \mathrm{X}$ dilution (Abcam: ab185716), which is a marker for osteoclasts, and a rabbit polyclonal primary antibody against RANKL at $100 \mathrm{X}$ dilution (Bioss: bs-0747R), which is a marker for osteoblasts, followed by counterstaining with hematoxylin. TRAP-positive, multinucleated ( $>3$ nuclei) cells present on the surface of the bone tissue were defined as osteoclasts. RANKL-positive, mononuclear cells present on the surface of the bone tissue were defined as osteoblasts.

Statistical analysis. The Mann-Whitney $U$-test was performed between each group. All statistical analyses were performed with SPSS version 24.0 (IBM Corp., Armonk, NY, USA). All $p$-values $<0.05$ were considered statistically significant.

\section{Results}

Effect of abiraterone in addition to androgen deprivation therapy on cancellous bone in mice. In oral gavage administration, the $\mathrm{BV} / \mathrm{TV}$ ratio of the abiraterone group, castration group, and castration+abiraterone group was significantly lower than that in the control group on day 21 ( $p=0.04, p=0.03$, and $p<0.001$; Figure $1 \mathrm{~A}$ ). The $\mathrm{BV} / \mathrm{TV}$ ratio in the castration+abiraterone group was not significantly different from that in the castration group (Figure 1A).

The $\Delta$ day 0-21 BV/TV of the abiraterone, castration, and castration+abiraterone groups significantly decreased compared to that in the control group $(p=0.02, p<0.001$, and $p<0.001$; Figure $1 \mathrm{~B})$. The $\Delta$ day $0-21 \mathrm{BV} / \mathrm{TV}$ in the castration+abiraterone group was not significantly different from that in the castration group (Figure 1B).

The serum testosterone levels in the castration and the castration+abiraterone groups were significantly lower than those in the control group ( $p<0.001, p<0.001$; Figure 1C). The testosterone level in the castration+abiraterone group was significantly lower than that in the castration group ( $p=0.03$, Mann-Whitney $U$-test; Figure 1C).

The serum RANKL level did not significantly differ between groups (Figure 1D). The serum TRAP5b level in the abiraterone group was not significantly different from that in the control group (Figure 1E). The serum TRAP5b level in the castration and the castration+abiraterone groups was significantly higher than those in the control group $(p<0.001$ and $p<0.001$; Figure 1E). There was no significant difference in the serum TRAP5b level in the castration+abiraterone group compared to that in the castration group. The serum OPG level in the castration group was not significantly different from that in the control group. The serum OPG level of the castration+abiraterone group was significantly higher than that in the control group ( $p=0.002$; Figure $1 \mathrm{~F}$ ).

The mean plasma abiraterone level was $7.0 \mathrm{ng} / \mathrm{ml}$ in all mice and $11.6 \mathrm{ng} / \mathrm{ml}$ in the measurable mice which could be sufficient physiological blood level by the $400 \mathrm{mg} / \mathrm{kg} /$ day oral gavage administration (15). There were two mice where plasma abiraterone levels were not measurable for unknown reason. In contrast, the mean plasma level was as low as 5.5 $\mathrm{ng} / \mathrm{ml}$ in the $200 \mathrm{mg} / \mathrm{kg} /$ day administration (14) (Figure 1G).

The number of osteoclasts and osteoblasts in the lower limbs in mice. The number of osteoclasts in the murine femur cross-section specimens in the abiraterone, castration, and castration+abiraterone groups was significantly higher than those in the control group ( $p<0.001, p<0.001$, and $p<0.001$, Mann-Whitney $U$-test; Figures $2 \mathrm{~A}$ and $\mathrm{C}$ ). However, no significant difference was observed in the number of osteoclasts in the castration+abiraterone group, compared to the castration group (Figures 2A and C).

The number of osteoblasts in the murine femur crosssection specimens in the abiraterone, castration, and castration+abiraterone groups was significantly higher than those in the control group $(p=0.01, p<0.001$, and $p=0.001$; Figures $2 \mathrm{~B}$ and D). However, no significant difference was observed in the number of osteoblasts in the castration+abiraterone group, compared to the castration group (Figures 2B and D).

\section{Discussion}

This study demonstrated that castration in the murine model stimulated osteoclast proliferation and reduced BMD due to the increased activity of osteoblasts and osteoclasts, and revealed the same results as previous reports (6). However, the obvious additional effects of abiraterone on castration, which directly inhibit or stimulate osteoclasts, leading to a reduction or increase in BMD, were not observed in this study.

Some studies have shown an effective reduction in testosterone levels with $75 \mathrm{mg} / \mathrm{kg}$ oral administration of abiraterone (16). However, even $200 \mathrm{mg} / \mathrm{kg}$ abiraterone did not provide sufficient trough levels, as has been reported in humans (14). We therefore increased the concentration of abiraterone solvent to $400 \mathrm{mg} / \mathrm{kg}$, which made a sufficient trough level (15). In the oral gavage study, no BMD reduction was observed in the control group. The castration increased the number of RANKL-positive osteoblasts, TRAP-positive osteoclasts, and serum TRAP5b level, and reduced BMD. The abiraterone monotherapy increased RANKL-positive osteoblasts and reduced BMD. However, no significant additional effect of abiraterone on the BMD, bone markers, and the number of osteoblasts and osteoclasts was observed in the castration+abiraterone group, compared with the castration group.

In the beginning, the assumption of this study was that the mice had been previously believed to be deficient in the secretion of adrenal androgens (17). Unexpectedly, the serum testosterone level in the castration+abiraterone group was 
found to be significantly lower than that in the castration group, although the difference was very small. A recent report showed that a small amount of androgen was produced from the adrenal gland in the murine castration model, the addition of adrenalectomy to castration lowered serum testosterone levels, and the adrenalectomy inhibited CRPC xenograft (18). The proportion of adrenal testosterone in mice was calculated to be less than $5 \%$ in the results of this experiment. In clinical practice, the serum testosterone levels in healthy humans, at an average of $383 \mathrm{ng} / \mathrm{dl}$ (19), decreased to an average of 7.6 $\mathrm{ng} / \mathrm{dl}$ after castration in the COU-AA-301 study of patients with CRPC (20). Moreover, serum testosterone levels averaged $7 \mathrm{ng} / \mathrm{dl}$ after castration and before abiraterone, decreasing to less than $1 \mathrm{ng} / \mathrm{dl}$ after abiraterone in the phase I study of abiraterone therapy (21). Therefore, the ratio of human adrenal testosterone was also calculated to be $5 \%$ or less. Although serum testosterone levels alone cannot explain the androgen-induced microenvironment in osteoblasts and osteoclasts, the human bone microenvironment was affected by testosterone levels in this mice experiment. From these results, it can be concluded that androgen-dependent osteoclast stimulation is already fully saturated by the castration, and no additional effects of abiraterone could be observed in murine osteoblasts and osteoclasts.

In the previous in vitro study by Iluniani et al., the expression of CYP17A1 in human osteoblasts suggested that at least some androgen-independent non-canonical mechanisms of abiraterone, unrelated to CYP17A1, were present in the bone microenvironment and suppressed osteoblasts and osteoclasts in an androgen-independent manner (13). Although the direct effect of abiraterone in the bone microenvironment could be subtracted by the deprivation of adrenal androgen in mice, the present in vivo study showed no obvious androgen-independent non-canonical mechanisms after addition of abiraterone to castration. Considered in line with the result of androgen-dependent mechanisms, it is possible that the androgen-dependent small osteoclaststimulating effect and the androgen-independent small osteoclast-inhibiting effect canceled each other out.

In the ERA223 trial, it was reported that the use of radium 223 in patients treated with abiraterone+ADT increased the frequency of fractures (22). It is considered that the use of radium 223 in combination with abiraterone causes excessive suppression of osteoclasts. Previous studies have reported that radium 223 suppresses the vicious cycle of prostate cancer bone metastasis in the bone microenvironment by breaking double-stranded DNA in osteoblasts, osteoclasts, and prostate cancer cells (14). However, the results in this study did not explain the increased fractures in the ERA223 trial. The results in this study support the almost similar results, in respect to SREs, obtained from the LATITUDE (10) and STAMPEDE trials (11) for administering abiraterone to patients with HNPC, which suggests that the effects of abiraterone to improve the time to SREs could be due to its inhibitory effect on cancer cells and not affected by its direct effect to the bone microenvironment.

The limitations of this research are as follows. First, the mice testosterone levels did not reach a level that was lower than the limit with abiraterone treatment, with or without castration, as previously reported in mice and humans (19). We used an intraperitoneal administration of abiraterone in this study, however, the results are not shown because of a $\mathrm{BMD}$ reduction in the control group. In experiments of oral administration in humans, a previous report showed that testosterone levels were different depending on the dose of abiraterone (23). The reason for this could be in the varied serum abiraterone level due to the varied ability of absorption in the oral gavage model (24). Second, a significant increase in serum RANKL levels induced by castration was not observed in this study (6). The large basal difference in the serum RANKL level might be one of the reasons for this. Third, corticosteroids were not co-administered, preventing adrenal insufficiency in this murine study, which made it unlike a real-world clinical study. Regarding the effect of corticosteroids on the onset of SREs, it has been reported that the combined use of prednisolone over $10 \mathrm{mg}$ /day increases the frequency of fractures in humans (25).

Taken together, in this murine study, the androgenindependent non-canonical direct suppression of osteoclasts leading to the inhibition of BMD reduction was not obviously observed after the addition of abiraterone to ADT. The androgen-dependent stimulation of the osteoclasts leading to the reduction of BMD was observed after a single treatment of abiraterone, but not after the addition of abiraterone to ADT. Although the administration of zoledronic acid or denosumab at the begging of ADT in clinical practice is essential for preventing the stimulation of osteoclasts, this murine study suggests that clinicians do not have to consider an additional BMD reduction when adding abiraterone to ADT.

\section{Conclusion}

The addition of abiraterone to castration did not alter the osteoclast activity and did not affect the BMD in the murine model.

\section{Funding}

This work was supported by Grant Numbers 15K10617 and 16H02679 from the Japanese Society for the Promotion of Science.

\section{Conflicts of Interest}

The Authors declare that there are no conflicts of interest regarding this study. 


\section{Authors' Contributions}

Conceptualization: Shiori Nakajima and Takamitsu Inoue; Data Curation: Shiori Nakajima and Takamitsu Inoue; Formal Analysis: Shiori Nakajima and Takamitsu Inoue; Funding Acquisition: Takamitsu Inoue and Tomonori Habuchi; Investigation: Shiori Nakajima, Mingguo Huang, Koichiro Takayama, Soki Kashima, and Takamitsu Inoue; Methodology: Shiori Nakajima, Koichiro Takayama, Soki Kashima, and Takamitsu Inoue; Project Administration: Shiori Nakajima, Takamitsu Inoue, Shintaro Narita, and Tomonori Habuchi; Software: Shiori Nakajima, Ryohei Yamamoto, Taketoshi Nara, and Takamitsu Inoue; Supervision: Shintaro Narita, Kazuyuki Numakura, Mitsuru Saito, Shigeru Satoh, and Tomonori Habuchi; Visualization: Shiori Nakajima, Atsushi Koizumi, and Takamitsu Inoue; Writing - Original Draft Preparation: Shiori Nakajima and Takamitsu Inoue; Writing Review \& Editing: Takamitsu Inoue, Shintaro Narita, and Tomonori Habuchi; All Authors have read and approved the final version of the manuscript.

\section{Acknowledgements}

The Authors thank Yoko Mitobe, Sayaka Fukuda, and Masako Nagata for their contribution in animal experiments and preparations.

\section{References}

1 Huggins C and Hodges CV: Studies on prostate cancer: I. The effect of castration, of estrogen and of androgen injection on serum phosphatases in metastatic carcinoma of the prostate. Cancer Res 1: 293-297, 1941. PMID: 12050481. DOI: 10.1016/ s0022-5347(05)64820-3

2 Traish AM, Guay A, Feeley R and Saad F: The dark side of testosterone deficiency: I. Metabolic syndrome and erectile dysfunction. J Androl 30(1): 10-22, 2008. PMID: 18641413. DOI: $10.2164 /$ jandrol.108.005215

3 Morote J, Morin JP, Abascal JM, Salvador C, Trilla E, Raventos CX, Cecchini L, Encabo G and Reventos J: Prevalence of osteoporosis during long-term androgen deprivation therapy in patients with prostate cancer. Urology 69(3): 500-504, 2007. PMID: 17382153. DOI: 10.1016/j.urology.2006.11.002

4 Proell V, Xu H, Schuler C, Weber K, Hofbauer LC and Erben RG: Orchiectomy upregulates free soluble RANKL in bone marrow of aged rats. Bone 45(4): 677-681, 2009. PMID: 19501680. DOI: 10.1016/j.bone.2009.05.024

5 Li X, Ominsky MS, Stolina M, Warmington KS, Geng Z, Niu QT, Asuncion FJ, Tan HL, Grisanti M, Dwyer D, Adamu S, Ke HZ, Simonet WS and Kostenuik PJ: Increased RANK ligand in bone marrow of orchiectomized rats and prevention of their bone loss by the RANK ligand inhibitor osteoprotegerin. Bone 45(4): 669-676, 2009. PMID: 19539794. DOI: 10.1016/j.bone. 2009.06.011

6 Takayama K, Inoue T, Narita S, Maita S, Huang M, Numakura K, Tsuruta H, Saito M, Maeno A, Satoh S, Tsuchiya N and Habuchi T: Inhibition of the RANK/RANKL signaling with osteoprotegerin prevents castration-induced acceleration of bone metastasis in castration-insensitive prostate cancer. Cancer Lett 397: 103-110, 2017. PMID: 28373003. DOI: 10.1016/j.canlet. 2017.03.034
7 Ottewell PD, Wang N, Meek J, Fowles CA, Croucher PI, Eaton $\mathrm{CL}$ and Holen I: Castration-induced bone loss triggers growth of disseminated prostate cancer cells in bone. Endocr Relat Cancer 21(5): 769-781, 2014. PMID: 25052474. DOI: 10.1530/ERC-140199

8 Prostate Cancer Trialists' Collaborative Group: Maximum androgen blockade in advanced prostate cancer: an overview of 22 randomised trials with 3283 deaths in 5710 patients. Lancet 346(8970): 265-269, 1995. PMID: 7630245.

9 Sweeney CJ, Chen YH, Carducci M, Liu G, Jarrard DF, Eisenberger M, Wong YN, Hahn N, Kohli M, Cooney MM, Dreicer R, Vogelzang NJ, Picus J, Shevrin D, Hussain M, Garcia JA and DiPaola RS: Chemohormonal therapy in metastatic hormone-sensitive prostate cancer. N Engl J Med 373(8): 737-746, 2015. PMID: 26244877. DOI: 10.1056/ NEJMoa 1503747

10 Fizazi K, Tran N, Fein L, Matsubara N, Rodriguez-Antolin A, Alekseev BY, Özgüroğlu M, Ye D, Feyerabend S, Protheroe A, De Porre P, Kheoh T, Park YC, Todd MB, Chi KN and LATITUDE Investigators: Abiraterone plus prednisone in metastatic, castration-sensitive prostate cancer. N Engl J Med 377(4): 352-360, 2017. PMID: 28578607. DOI: 10.1056/ NEJMoa1704174

11 Sydes MR, Spears MR, Mason MD, Clarke NW, Dearnaley DP, de Bono JS, Attard G, Chowdhury S, Cross W, Gillessen S, Malik ZI, Jones R, Parker CC, Ritchie AWS, Russell JM, Millman R, Matheson D, Amos C, Gilson C, Birtle A, Brock S, Capaldi L, Chakraborti P, Choudhury A, Evans L, Ford D, Gale J, Gibbs S, Gilbert DC, Hughes R, McLaren D, Lester JF, Nikapota A, O'Sullivan J, Parikh O, Peedell C, Protheroe A, Rudman SM, Shaffer R, Sheehan D, Simms M, Srihari N, Strebel R, Sundar S, Tolan S, Tsang D, Varughese M, Wagstaff J, Parmar MKB, James ND and STAMPEDE Investigators: Adding abiraterone or docetaxel to long-term hormone therapy for prostate cancer: directly randomised data from the STAMPEDE multi-arm, multi-stage platform protocol. Ann Oncol 29(5): 1235-1248, 2018. PMID: 29529169. DOI: 10.1093/ annonc/mdy072

12 Saad F, Shore N, Van Poppel H, Rathkopf DE, Smith MR, de Bono JS, Logothetis CJ, de Souza P, Fizazi K, Mulders PF, Mainwaring P, Hainsworth JD, Beer TM, North S, Fradet Y, Griffin TA, De Porre P, Londhe A, Kheoh T, Small EJ, Scher HI, Molina A and Ryan CJ: Impact of bone-targeted therapies in chemotherapy-naïve metastatic castration-resistant prostate cancer patients treated with abiraterone acetate: Post hoc analysis of study COU-AA-302. Eur Urol 68(4): 570-577, 2015. PMID: 25985882. DOI: 10.1016/j.eururo.2015.04.032

13 Iuliani M, Pantano F, Buttigliero C, Fioramonti M, Bertaglia V, Vincenzi B, Zoccoli A, Ribelli G, Tucci M, Vignani F, Berruti A, Scagliotti GV, Tonini G and Santini D: Biological and clinical effects of abiraterone on anti-resorptive and anabolic activity in bone microenvironment. Oncotarget 6(14): 12520-12528, 2015. PMID: 25904051. DOI: 10.18632/oncotarget.3724

14 Suominen MI, Fagerlund KM, Rissanen JP, Konkol YM, Morko JP, Peng Z, Alhoniemi EJ, Laine SK, Corey E, Mumberg D, Ziegelbauer K, Käkönen SM, Halleen JM, Vessella RL and Scholz A: Radium-223 inhibits osseous prostate cancer growth by dual targeting of cancer cells and bone microenvironment in mouse models. Clin Cancer Res 23(15): 4335-4346, 2017. PMID: 28364014. DOI: 10.1158/1078-0432.CCR-16-2955 
15 Carton E, Noe G, Huillard O, Golmard L, Giroux J, Cessot A, Saidu NE, Peyromaure M, Zerbib M, Narjoz C, Guibourdenche J, Thomas A, Vidal M, Goldwasser F, Blanchet B and Alexandre $\mathrm{J}$ : Relation between plasma trough concentration of abiraterone and prostate-specific antigen response in metastatic castrationresistant prostate cancer patients. Eur J Cancer 72: 54-61, 2017. PMID: 28027516. DOI: 10.1016/j.ejca.2016.11.027

16 Spade DJ, Hall SJ, Saffarini CM, Huse SM, McDonnell EV and Boekelheide K: Differential response to abiraterone acetate and di-n-butyl phthalate in an androgen-sensitive human fetal testis xenograft bioassay. Toxicol Sci 138(1): 148-160, 2014. PMID: 24284787. DOI: $10.1093 /$ toxsci/kft266

17 Weerden WM, Bierings HG, Steenbrugge GJ, Jong FH and Schroder FH: Adrenal glands of mouse and rat do not synthesize androgens. Life Sci 50(12): 857-861, 1992. DOI: 10.1016/00243205(92)90204-3

18 Huhtaniemi R, O.R., Knuuttila M, Mehmood A, Aho E, Laajala TD, Nicorici D, Aittokallio T, Laiho A, Elo L, Ohlsson C, Kallio $\mathrm{P}$, Mäkelä S, Mustonen MVJ, Sipilä P and Poutanen M: Adrenals contribute to growth of castration-resistant $\mathrm{VCaP}$ prostate cancer xenografts. Am J Pathol 188(12): 2890-2901, 2018. PMID: 30273606. DOI: 10.1016/j.ajpath.2018.07.029

19 Page ST, Bremner WJ, Clark RV, Bush MA, Zhi H, Caricofe RB, Smith PM and Amory JK: Nanomilled oral testosterone plus dutasteride effectively normalizes serum testosterone in normal men with induced hypogonadism. J Androl 29(2): 222-227, 2007. PMID: 18077826. DOI: 10.2164/jandrol.107.002956

20 Ryan CJ, Molina A, Li J, Kheoh T, Small EJ, Haqq CM, Grant RP, de Bono JS and Scher HI: Serum androgens as prognostic biomarkers in castration-resistant prostate cancer: results from an analysis of a randomized phase III Trial. J Clin Oncol 31(22): 2791-2798, 2013. PMID: 23816964. DOI: 10.1200/JCO. 2012.45.4595

21 Attard G, Reid AH, Yap TA, Raynaud F, Dowsett M, Settatree S, Barrett M, Parker C, Martins V, Folkerd E, Clark J, Cooper CS, Kaye SB, Dearnaley D, Lee G and de Bono JS: Phase I clinical trial of a selective inhibitor of CYP17, abiraterone acetate, confirms that castration-resistant prostate cancer commonly remains hormone driven. J Clin Oncol 26(28): 45634571, 2008. PMID: 18645193. DOI: 10.1200/JCO.2007.15.9749
22 Smith M, Parker C, Saad F, Miller K, Tombal B, Ng QS, Boegemann M, Matveev V, Piulats JM, Zucca LE, Karyakin O, Kimura G, Matsubara N, Nahas WC, Nolè F, Rosenbaum E, Heidenreich A, Kakehi Y, Zhang A, Krissel H, Teufel M, Shen J, Wagner V and Higano C: Addition of radium-223 to abiraterone acetate and prednisone or prednisolone in patients with castration-resistant prostate cancer and bone metastases (ERA 223): a randomised, double-blind, placebo-controlled, phase 3 trial. Lancet Oncol 20(3): 408-419, 2019. PMID: 30738780. DOI: 10.1016/S1470-2045(18)30860-X

23 O’Donnell A, Judson I, Dowsett M, Raynaud F, Dearnaley D, Mason M, Harland S, Robbins A, Halbert G, Nutley B and Jarman M: Hormonal impact of the $17 \alpha$-hydroxylase/C17,20lyase inhibitor abiraterone acetate (CB7630) in patients with prostate cancer. Br J Cancer 90(12): 2317-2325, 2004. PMID: 15150570. DOI: $10.1038 /$ sj.bjc.6601879

24 Merseburger AS, Hammerer P, Rozet F, Roumeguère T, Caffo $\mathrm{O}$, da Silva FC and Alcaraz A: Androgen deprivation therapy in castrate-resistant prostate cancer: how important is $\mathrm{GnRH}$ agonist backbone therapy? World J Urol 33(8): 1079-1085, 2015. PMID: 25261259. DOI: 10.1007/s00345-014-1406-2

25 Strehl C, Bijlsma JW, de Wit M, Boers M, Caeyers N, Cutolo M, Dasgupta B, Dixon WG, Geenen R, Huizinga TW, Kent A, de Thurah AL, Listing J, Mariette X, Ray DW, Scherer HU, Seror R, Spies CM, Tarp S, Wiek D, Winthrop KL and Buttgereit F: Defining conditions where long-term glucocorticoid treatment has an acceptably low level of harm to facilitate implementation of existing recommendations: viewpoints from an EULAR task force. Ann Rheum Dis 75(6): 952-957, 2016. PMID: 26933146. DOI: $10.1136 /$ annrheumdis-2015-208916

Received August 21, 2020

Revised September 10, 2020

Accepted September 14, 2020 